\title{
Climate affects seabird population dynamics both via reproduction and adult survival
}

\author{
Hanno Sandvik $^{1, *}$, Kjell Einar Erikstad ${ }^{2}$, Bernt-Erik Sæther ${ }^{1}$ \\ ${ }^{1}$ Centre for Conservation Biology, Norwegian University of Science and Technology (NTNU), 7049 Trondheim, Norway \\ ${ }^{2}$ Norwegian Institute for Nature Research (NINA), FRAM, High North Research Centre for Climate and the Environment, \\ 9296 Tromsø, Norway
}

\begin{abstract}
Climate variability can affect population dynamics via adult survival or via offspring production and recruitment. The relative importance of both processes is still an unresolved matter, especially in long-lived species, where the time lags between the climate signal and the population response differ greatly depending on the process involved. We address the issue using 378 time series from 29 seabird species from 187 breeding colonies throughout the North Atlantic. The effect of climate on population growth rate is estimated as the slope of the North Atlantic Oscillation (NAO) index at different time lags when used as a covariate in population models. Using nonlinear mixed effects models, we can demonstrate that climate affects the population dynamics of seabirds, both through adult survival and through the recruitment of offspring produced. The latter effect is stronger, and the long time lags involved make it likely that its magnitude is still underestimated. Because different processes are involved, the sign of the relationship with the NAO differs between time lags. The relationship between the NAO and the population growth rate is also highly variable, both within and across species. In a second analytical step, we address the factors that may cause this interspecific and inter-colony variation, considering the ecological, demographic and geographical characteristics of the populations. Among comparatively 'fastlived' seabirds, i.e. species with large clutches, the relationship with the NAO reverses its sign depending on latitude, while no such trend is apparent among 'slow' species.
\end{abstract}

KEY WORDS: Climatic responsiveness $\cdot$ Population growth rate $\cdot$ Recruitment $\cdot$ Age at maturity North Atlantic Oscillation · Time lag

Resale or republication not permitted without written consent of the publisher

\section{INTRODUCTION}

Climate can have profound effects on the demography and population dynamics of marine top predators. Effects of climate on seabirds have been documented in the timing of breeding, breeding proportion, breeding success and adult survival (e.g. Thompson \& Ollason 2001, Durant et al. 2004a, Lee et al. 2007, Monticelli et al. 2007, Gaston et al. 2009, Jenouvrier et al. 2009, Sydeman 2009, Wolf et al. 2009). Furthermore, reviews and comparative analyses of Atlantic seabirds have shown that such results are not merely isolated findings, but can be documented across species and populations, although the degree of climatic responsiveness may vary widely between different seabird taxa (Reid et al. 1999, Durant et al. 2004b, Sandvik \& Erikstad 2008, Sandvik et al. 2008a). Whereas many of the processes involved in modulating these demographic traits are increasingly well understood, it is still a long way to understanding the pathways of climatic influences on population dynamics as such. Population growth is a function of all life-history traits and, thus, integrates the environmental effects on all these parameters (Engen et al. 2009, Tuljapurkar et al. 2009), which, in addition, may operate at different time lags (Post 2004). 
An important question in both life-history theory and global change research regards the relative importance of environmental influences on population dynamics via offspring production and recruitment on the one hand and via adult survival on the other (Stearns 1992, Weimerskirch et al. 2003, Sæther \& Engen 2010b). The effect of variability in a life-history trait $a$ on the variance of population growth rate $(\lambda)$, and thus fitness, is a function both of the variability of $a$ and of this trait's elasticity $e$ (relative importance for the population growth rate). In matrix notation, this dependence can be approximated as (Caswell 2001, p. 225):

$$
\operatorname{Var}(\lambda) \approx \sum_{i, j}\left[\left(\mathrm{e}_{i j} \cdot \lambda / a_{i j}\right) \cdot \operatorname{Var}\left(a_{i j}\right)\right]
$$

At the same time, the most elastic life-history trait is predicted to be under the strongest selection pressure against temporal variability (Jonsson \& Ebenman 2001), so that one usually finds a negative correlation between a life-history trait's elasticity and its variability (Pfister 1998, Sæther \& Bakke 2000). It is therefore not straightforward to predict the balance of demographic elasticity versus climatic responsiveness in shaping population dynamics: while a trait must be temporally variable in order to be responsive to environmental conditions such as climate, it must have a high elasticity if it is to affect the population growth rate.

The current study aims at examining whether seabird population dynamics are more strongly influenced by climate via adult survival or offspring production and recruitment. This is addressed using a modelling approach based on a large sample of time series on seabird population counts across the North Atlantic. The problem is approached by comparing the relationship between the North Atlantic Oscillation (NAO) index and population growth rates across different time lags. If climatic effects on adult survival are most important, the relevant time lag of climatic effects on population dynamics will most often be zero (assuming a direct effect of weather) or $1 \mathrm{yr}$ (assuming indirect effects via the food chain). If climatic effects on offspring production are more important, however, the population dynamics are expected to be affected most strongly by the climatic conditions several years ago, where the number of intervening years is equal to the age at recruitment. This follows from the fact that the effect of climate on offspring production will not become apparent in population counts before the offspring affected has actually recruited to the population being censusedprovided that the signal is not lost during the prolonged pre-breeding life-span of seabirds. With off- spring production we here refer to the size of the cohort fledged in a certain year, which is the product of half the adult population size, the breeding proportion, clutch size, hatching success and fledging success, all of which can be affected by climate. With recruitment we refer to the number of birds that have not previously bred entering the breeding population in a given year, which, in turn, is determined by the initial size of the cohort recruited, pre-breeding survival and philopatry, and establishment success.

The second step of the analyses examines whether it is possible to detect general patterns in the climatic responsiveness of seabird population dynamics. Climatic responsiveness varies considerably between different species (Kitaysky \& Golubova 2000, Jenouvrier et al. 2005a, Sandvik et al. 2005, Sandvik \& Erikstad 2008, Sæther \& Engen 2010b), but also between different populations of the same species (Mysterud et al. 2000, Sæther et al. 2003, Harris et al. 2005, Sandvik et al. 2008a, Grøtan et al. 2009). It is important to acquire better knowledge of the differential climatic responsiveness of species and populations. Taxonomy, geography, foraging ecology and life history are among the factors that may help to predict climatic responsiveness and to derive lawful (nomothetic) generalisations in climate ecology. The causal and mechanistic understanding of the links between climate and population dynamics will remain incomplete unless commonalities and differences between species and populations are addressed.

We approach these problems by analysing an interspecific dataset. Addressing the issue comparatively makes the study nomothetic rather than merely descriptive, i.e. it generalises across species. The results demonstrate that the climatic response in seabird population dynamics is indeed geographically patterned and that life-history characteristics lead to differential responses across species.

\section{METHODS}

The present comparative study is based on published time series of population estimates of North Atlantic seabirds. In order to obtain reliable estimates of population parameters, only time series of at least 12 yr length were included. The resulting data base contained 378 time series from 187 locations and 29 species. The median length of the time series was 19 yr (mean: 25 yr; maximum: 75 yr; in total 9320 observation-years). The colonies ranged from Florida $\left(27.9^{\circ} \mathrm{N}, 80.7^{\circ} \mathrm{W}\right)$ in the southwest to Spitsbergen $\left(78.9^{\circ} \mathrm{N}\right)$ in the north and the Kola Peninsula $\left(37.3^{\circ} \mathrm{E}\right)$ 
in the east (see Fig. S1 in Supplement 1 at www.intres.com/articles/suppl/m454p273_supp.pdf). The species included Alcinae (auks: Alca torda, Cepphus grylle, Fratercula arctica, Uria aalge, U. lomvia), Hydrobatinae (northern storm-petrels: Hydrobates pelagicus), Larinae (gulls: Larus argentatus, L. canus, L. fuscus, L. marinus, L. minutus, L. ridibundus, Rissa tridactyla), Pelecanus (pelicans: Pelecanus occidentalis), Phalacrocoracinae (cormorants: Phalacrocorax carbo, Stictocarbo aristotelis), Procellariidae (petrels: Calonectris diomedea, Fulmarus glacialis, Pterodroma madeira), Stercorariinae (skuas: Stercorarius parasiticus), Sterninae (terns: Chlidonias niger, Sterna albifrons, S. caspia, S. dougallii, S. hirundo, S. nilotica, S. paradisaea, S. sandvicensis) and Sulidae (gannets: Morus bassanus). See Supplement 1 for population time series included in the analyses and their sources.

\section{Population modelling}

For each of the 378 population time series, 25 separate logistic population models were fitted. The 25 models per population included 1 climatic covariate each, viz. NAO at time lags from 0 to $24 \mathrm{yr}$. Most of the 25 time lags were assumed to be biologically irrelevant for the populations modelled. They were included in order to be able to correct for the occurrence of correlational artefacts (see below). The logistic population models had the form $N_{t+1}=\lambda_{t} N_{t}$ where $N_{t}$ is the population size in year $t_{1}$ and $\lambda_{t}$ is the population growth rate in year $t$ :

$$
\lambda_{t}=\mathrm{e}^{r\left(1-N_{t} / K\right)+\beta Z_{t-\tau}+\varepsilon}
$$

with $\beta$, slope of the covariate $Z_{i}$ e, base of the natural $\log$ arithm; $\varepsilon$, independent variable with zero mean and variance $\sigma_{\text {res }}^{2}$ (which is the part of environmental variance $\sigma_{\mathrm{e}}^{2}$ that is not accounted for by $Z$ ); $K$, carrying capacity; $r$, intrinsic population growth rate; $\tau$, number of years the NAO is lagged against the population time series; and $Z_{t}$ NAO index in year $t$. The parameters $\beta, K, r$ and $\sigma_{\text {res }}$ were estimated from each population times series using maximum likelihood such that the log-likelihood:

$$
\ln L \propto-\sum_{k=2}^{n}\left\{\ln \sigma_{\text {res }}^{2}+\left[\ln N_{k}-\mathrm{E}\left(\ln N_{k}\right)\right]^{2} / \sigma_{\text {res }}^{2}\right\}
$$

was maximised over the $n$ elements of the time series (Sæther et al. 2009), where $\mathrm{E}\left(\ln N_{k}\right)=\ln \left(\lambda_{k-1} N_{k-1}\right)$ is the predicted log-population size based on the observed population size $N_{k-1}$ and Eq. (2).

The logistic population model was chosen because it has previously been shown to describe the pattern of density regulation in avian population dynamics quite well (Sæther \& Engen 2002). The model of Eq. (2) is based on the implicit assumption that population sizes $N_{t}$ are measured without error. While this assumption is met in very few populations, mainly because of intermittent breeding, we have not attempted to correct for this source of noise. We contend that, while observation error makes the data more noisy, this will to a certain degree be outweighed by the large sample size and does not introduce any systematic error.

\section{Definition of variables}

The extended winter (December to March) NAO index was used as the environmental covariate of the population models (Hurrell 2005). This index was chosen because many studies have identified the winter NAO to have huge biological significance (e.g. Ottersen et al. 2001, Sandvik \& Erikstad 2008), and because the signal:noise ratio of the NAO is strongest in winter (Barnston \& Livezey 1987, Hurrell et al. 2003). The estimated slope $\beta$ (Eq. 2) of the standardised climatic covariate was used as a measure of climatic effects on population dynamics. We refer to this slope as relationship to the NAO. It is close to +1 if the population growth rate increases proportionally with the NAO index and -1 if the relation is inverse.

A second measure, referred to as climatic responsiveness, was defined in a way that preserves the magnitude, but ignores the sign of the climate effects. Because $|\beta|$ or $\beta^{2}$ yield distributions that are truncated at zero, climate responsiveness was defined as $1+\ln |\beta|$. This measure thus approaches $-\infty$ if population growth rate is entirely unrelated to the NAO index. It is positive if the population growth rate is strongly affected by the NAO index, irrespective of the direction of this relationship.

The relationship with the NAO and climatic responsiveness were entered as dependent variables into the following analyses, which aimed at explaining the variation in these measures among populations and species. Explanatory variables considered were body mass, life history, foraging distance, diving depth, latitude and longitude. Body mass, foraging distance and diving depth were log-transformed. Life history was defined as the first axis in a principal component analysis (PCA) incorporating the species' ages at maturity and clutch size. Large positive values of 'life history' indicate species at the fast end of the slow-fast life-history continuum (e.g. large clutch 
size and low age at maturity; Sæther \& Bakke 2000, Bennett \& Owens 2002; for details on the PCA see Supplement 2 at www.int-res.com/articles/suppl/ m454p273.pdf). Ages at maturity were the best estimates of each species' median age at first breeding (not physiological maturity). Longitude was, because of this measure's bimodal distribution, replaced by a binary variable (American vs. European coast). Because local estimates of the explanatory variables were unavailable for most colonies, life-history traits and foraging ecology of the species were inferred from the literature (Poole \& Gill 1992-2003, Schreiber \& Burger 2002). Some of the variables were unavailable in a few species, and these were extrapolated based on a phylogeny of the related species (cf. Supplement 2).

\section{Time lags and covariates of climatic effects}

The effect of climate was investigated using nonlinear mixed-effects models (Pinheiro et al. 2006), analysing the climate effects estimated at all 25 time lags of all 378 populations simultaneously, with population as random factor and taking account of the correlation structure between the different time lags within each population by assuming an autoregressive process of order 1. Species, higher taxon and region (North Sea, Baltic Sea, Barents Sea, etc.) were also tested as nested random factors in addition to population. The non-linear function used was a bell curve centred on the time lag $t=t_{0}+t_{1} \alpha$ and with a variance of 0.5 (Fig. 1, Supplement 2):

$$
f(i, \tau)=\kappa+\left(b_{0}+\sum_{k} b_{k} X_{k}\right) \cdot \mathrm{e}^{-\left(\tau-t_{0}-t_{1} \alpha(i)\right)^{2}}+U_{i}+\varepsilon_{i \tau}
$$

with $\alpha(i)$, age at maturity of population $i_{i} b=b_{0}+$ $\sum b_{k} X_{k}$, magnitude of the population response to climate $\left(b_{0}\right.$ being the intercept and $b_{\mathrm{k}}$ the slope of the response on covariate $\left.X_{k}\right) ; \varepsilon_{i \tau}$, residual error; $f(i, \tau)$, response, i.e. climatic responsiveness or relationship with the NAO, of population $i$ to the NAO conditions prevailing $\tau$ years ago; $i$, population (dummy variable used as identifier); $\kappa$, background correlation across all time lags; $t=t_{0}+t_{1} \alpha$, time lag of the population response $\left(t_{0}\right.$ being the intercept and $t_{1}$ the slope of time lag on age at maturity $\alpha$ ); $\tau$, number of years the NAO was lagged against the population time series; $U_{i ı}$ population-specific random effect; and $X_{k \prime}$ explanatory variable $k$. The choice of a variance of 0.5 was arbitrary.

Using this model, the magnitude of climate effects can be estimated simultaneously with the relevant time lag. The occurrence of correlational artefacts is buffered by the nuisance variable $\kappa$, which allows the unbiased estimation of the magnitude of climate effects (b) by subtraction of $\kappa$ (Fig. 1). In other words, $b$ is a measure of the magnitude of the effects of climate at time $t$ on population growth over and above the effects (real or artifactual) that climate at the other 24 time lags was estimated to have. The model equation can also be used to specify a null model (letting $b_{0}, b_{i}, t_{0}, t_{1}=0$ ) or test fixed time lags (letting $t_{1}=$ 0 and $t_{0}=$ time lag).

Because of the complex model structure and high sample sizes, modelling was divided into 3 steps. (1) A non-linear mixed-effects model was used to test the relevance of different time lags without considering covariates $\left(b_{1}=0\right)$. (2) At time lags equalling $0 \mathrm{yr}, 1 \mathrm{yr}$ and each species' age at maturity, relevant covariates were searched for using linear fixedeffects models. (3) The results of the second analysis step were re-inserted in non-linear mixed-effects models to corroborate the previous findings. The results of the intermediate (second) step are not shown.

Time series length and data quality may influence the results obtained, because short time series may give rise to spurious correlations and because data

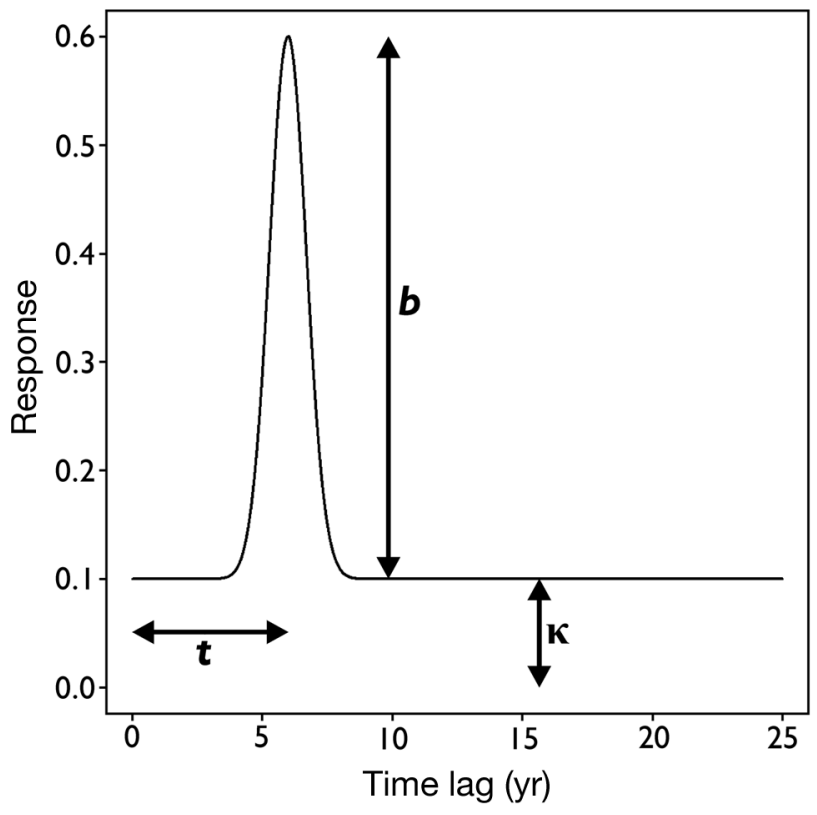

Fig. 1. Schematic presentation of the non-linear model structure used in explaining climate effects on population dynamics. The 3 parameters $b, \kappa$ and $t$ are estimated from the data. In order to account for correlational artefacts, the nuisance parameter $\kappa$ estimates the 'baseline correlation' across all time lags, including the biologically uninformative ones. The magnitude $b$ of climate effects is then estimated as the height of the peak over and above this baseline. Time lags $t$ can be specified, or estimated simultaneously with $b$ and $\kappa$ (cf. Eq. 1) 
obtained using poor sampling design may contain huge observation errors. We checked this by including time series length (number of years) and data quality (a score from 1 to 9; see column 'Type' in Table S1 in Supplement 1 at www.int-res.com/articles/ suppl/m454p273.pdf) as covariates. Both variables affected the nuisance parameter $\kappa$ in climatic responsiveness (length, $\mathrm{p}<10^{-12}$; quality, $\mathrm{p}=0.038$ ). This was not the case for the relationship with the NAO, nor did length or quality influence the magnitude of climatic responsiveness or of the relationship with the NAO at any time lag (all $\mathrm{p} \gg 0.1$ ). Because no parameters other than $\kappa$ were affected by the inclusion of length or quality, the latter variables were therefore omitted from the analyses.

\section{Model selection}

Model selection was based on Akaike's Information Criterion (AIC). We report $\triangle \mathrm{AIC}$ values relative to the null model (i.e. subtracting the AIC of a model excluding covariates from all other models' AICs), such that large negative $\triangle \mathrm{AIC}$ values indicate well-supported models. If 2 or more nested models deviated by $<2$ AIC units, the most parsimonious model was preferred, i.e. the one requiring fewest parameters.

The phylogenetic inertia of the relationship with the NAO and of climatic responsiveness was estimated as the variance explained by sister taxa. See Supplement 2 for more details and for the references used to infer the seabird phylogeny.

All computations were carried out in the $\mathrm{R}$ environment ( $\mathrm{R}$ Development Core Team 2006). Estimates are presented as means $\pm \mathrm{SE}$ throughout.

\section{RESULTS}

Climate effects were tested with 25 time lags, most of which must be assumed to be biologically irrelevant. The following analyses correct for potential biases by estimating and subtracting a general 'baseline correlation' across all time lags (nuisance parameter $\kappa_{i}$ Fig. 1).

In the first step of the analyses, the time lags at which climatic responsiveness was largest (i.e. at which most variability in population growth rate was explained by the climatic covariate) were identified (see Table 1). If no time lag was specified, the nonlinear model estimated the most important time lag to be only marginally different from zero $(0.75 \pm 0.42 \mathrm{yr}$, $\triangle \mathrm{AIC}=-1.13, \mathrm{p}=0.071)$. Specifying a fixed time lag of $1 \mathrm{yr}$ resulted in a better model $(\triangle \mathrm{AIC}=-2.52)$ than fixing the time lag at $0 \mathrm{yr}$, however $(\triangle \mathrm{AIC}=-0.04)$.

When the most important time lag was defined to be a function of each species' age at maturity, a wellsupported model was obtained $(\triangle \mathrm{AIC}=-2.66)$. Most importantly, the coefficient of age at maturity was highly significant $\left(1.45 \pm 0.25, \mathrm{p}<10^{-8}\right)$, and also the magnitude of climatic responsiveness was larger than at the remaining time lags $(0.16 \pm 0.06, \mathrm{p}=$ 0.0033). The intercept of the function was not different from zero $(-1.34 \pm 0.96, p=0.16)$. The model could be simplified further by recognising that the coefficient of age at maturity was only marginally different from unity $(0.45 \pm 0.25, \mathrm{p}=0.068)$. This simplified model was the best one overall $(\triangle \mathrm{AIC}=-2.72)$, but received very similar support as the model with a constant 1 yr time lag.

Climatic responsiveness was larger than at the remaining time lags for a time lag equalling $1 \mathrm{yr}$ or age at maturity $(>0.11 \pm 0.05, \mathrm{p}<0.04)$. This was not the case for the unlagged effect of climate $(0.08 \pm$ $0.06, \mathrm{p}=0.15)$.

In the next step, the importance of covariates in explaining the magnitude of the populations' climatic responsiveness was modelled. At fixed time lags of 0 and $1 \mathrm{yr}$, none of the covariates was able to explain

Table 1. Identification of the most relevant time lags of climatic responsiveness of population dynamics across 378 seabird populations. Each row represents estimates from 1 non-linear mixed-effects model. Numbers that were specified rather than estimated are given in square brackets. Time lags are either the same across all species $\left(0,1\right.$ and $t_{0}$ years) or a function of the age at maturity $\left(\alpha_{j}\right)$ of each species $j$. The magnitude of climatic effects is abbreviated as $b_{0}$ (no covariates were considered, i.e. $b_{1}=0$ ). See Eq. (4) and Fig. 1 for abbreviations used and their meaning. The nuisance parameter $\kappa$ was estimated as $-2.36 \pm 0.16$ in all models. $\triangle$ AIC (Akaike's information criterion) values are provided relative to the null model (i.e. containing only random effects and $\kappa$ as the sole main effect), which had 5 parameters and AIC $=29714.47$. The best models are in bold. Significance levels $=\mathrm{p}^{* * *}<0.001 \leq \mathrm{p}^{* *}<0.01 \leq \mathrm{p}^{*}<0.05 \leq$

$$
\left.\mathrm{p}^{+}<0.1\right)
$$

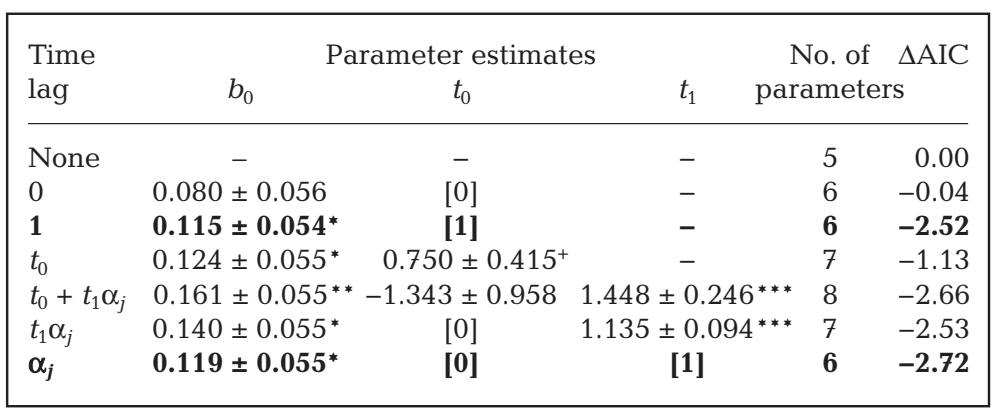


Table 2. Covariates explaining the magnitude of climatic responsiveness of population dynamics across 378 seabird populations. The climatic covariate (North Atlantic Oscillation) is lagged by each species' age at maturity (which means that all models are nested within the last model of Table 1). Each column represents estimates from 1 non-linear mixed-effects model.

Only the set of best models is shown. See Table 1 for further explanations

\begin{tabular}{|lcccc|}
\hline Parameter & \multicolumn{2}{c|}{ Parameter estimates } \\
\hline [Intercept] & $+1.21 \pm 0.60^{*}$ & $+0.66 \pm 0.51$ & $+0.53 \pm 0.47$ & $0.83 \pm 0.43^{+}$ \\
Body mass & $-0.023 \pm 0.075$ & $+0.061 \pm 0.058$ & $+0.078 \pm 0.051$ & - \\
Feeding depth & $-1.57 \pm 0.93^{+}$ & $+0.06 \pm 0.11$ & - & - \\
Body mass $\times$ Feeding depth & $+0.24 \pm 0.14^{+}$ & - & - & - \\
Latitude & $-0.018 \pm 0.008^{*}$ & $-0.017 \pm 0.008^{*}$ & $-0.016 \pm 0.008^{*}$ & $-0.013 \pm 0.008^{+}$ \\
No. of parameters & 10 & 9 & 8 & 7 \\
AIC & -3.35 & -2.25 & -3.92 & -3.55 \\
\hline
\end{tabular}

the variation in the magnitude of climate responsiveness, the best supported covariates being diving depth $(-0.099 \pm 0.091, \mathrm{p}=0.28)$ for unlagged climate and American versus European coast $(-0.23 \pm 0.24$, $p=0.33$ ) for Time Lag 1. Compared to the models with intercepts only (see Table 1), the models' AIC increased by at least 0.8 units. At time lags equal to each species' age at maturity, several models performed slightly better than the intercept-only model (Table 2), including effects of body mass, diving depth, their interaction and latitude. However, none of those models represented improvements by $>2$ AIC units. This means that the intercept-only model for climatic responsiveness lagged by age at maturity was preferred over the models in Table 2 .

In models of climatic responsiveness, a considerable amount of variation was observed at the levels of species (standard deviation, 0.27 ) and higher taxon $(0.37)$, in addition to the population level $(0.69$; residual $\mathrm{SD}, 1.11)$. These models therefore include 3 nested random effects.
Climatic responsiveness, as defined here (see 'Materials and methods'), ignores the sign of the climatic effect. When considering the relationship between population growth rate and the NAO, all 3 time lags turned out to be important (Table 3), and differences between the American and the European coasts of the North Atlantic appeared at all time lags. The unlagged relationship with the NAO was more positive at the European than at the American coasts of the North Atlantic, whereas the reverse was true for the relationship with the NAO lagged by 1 yr and by each species' age at maturity. At the latter time lag the relationship with the NAO was more positive in species with fast life histories (Table 3). However, closer inspection revealed that this positive relationship between life history and climate effect was most pronounced at low latitudes, while the relationship tended to be negative at high latitudes (Fig. 2). There was a weak tendency that larger species had a stronger relationship with the unlagged NAO (Table 3).

Table 3. Covariates explaining the relationship between the North Atlantic Oscillation and population growth rate across 378 seabird populations and at different time lags. Each column represents estimates from 1 non-linear mixed-effects model. $\Delta$ AIC values are provided relative to the null model (i.e. intercept and random effects only), which had 3 parameters and AIC $=-5990.71$. The best model is in bold. See Table 1 for further explanations

\begin{tabular}{|c|c|c|c|c|c|c|c|}
\hline \multirow{2}{*}{$\frac{\text { Time lag }}{0}$} & \multirow{2}{*}{$\begin{array}{c}\text { Parameter } \\
\text { [Intercept] }\end{array}$} & \multicolumn{6}{|c|}{ Parameter estimates } \\
\hline & & $-0.23 \pm 0.06^{* * *}$ & $-0.17 \pm 0.05^{* * *}$ & $-0.18 \pm 0.05^{* * *}$ & - & $-0.05 \pm 0.04$ & $-0.19 \pm 0.05^{* * *}$ \\
\hline 0 & Body mass & $+0.011 \pm 0.008$ & - & - & - & - & - \\
\hline 0 & Coast & $+0.17 \pm 0.05^{* * *}$ & $+0.17 \pm 0.05^{* * *}$ & $+0.18 \pm 0.05^{* * *}$ & - & $+0.05 \pm 0.04$ & $+0.19 \pm 0.05^{* * *}$ \\
\hline 1 & [Intercept] & $+0.18 \pm 0.04^{* * *}$ & $+0.18 \pm 0.04^{* * *}$ & $+0.19 \pm 0.04^{* * *}$ & $+0.07 \pm 0.03^{*}$ & - & $+0.20 \pm 0.04^{* * *}$ \\
\hline 1 & Coast & $-0.19 \pm 0.05^{* * *}$ & $-0.19 \pm 0.05^{* * *}$ & $-0.19 \pm 0.05^{* * *}$ & $-0.08 \pm 0.04^{*}$ & - & $-0.21 \pm 0.04^{* * *}$ \\
\hline$\alpha$ & [Intercept] & $+0.12 \pm 0.07^{+}$ & $+0.12 \pm 0.07^{+}$ & $+0.11 \pm 0.07$ & $+0.13 \pm 0.07^{+}$ & $+0.14 \pm 0.07^{+}$ & - \\
\hline$\alpha$ & Life history & $+0.15 \pm 0.06^{* *}$ & $+0.15 \pm 0.06^{* *}$ & $+0.18 \pm 0.05^{* * *}$ & $+0.15 \pm 0.06^{* *}$ & $+0.15 \pm 0.06^{* *}$ & - \\
\hline$\alpha$ & Latitude & $-0.000 \pm 0.001$ & $-0.000 \pm 0.001$ & $-0.001 \pm 0.001$ & $-0.000 \pm 0.001$ & $-0.000 \pm 0.001$ & - \\
\hline Lit & ife history $\times$ Latitude & $-0.003 \pm 0.001^{* *}$ & $-0.003 \pm 0.001^{* *}$ & $-0.003 \pm 0.001^{* *}$ & $-0.003 \pm 0.001^{* *}$ & $-0.003 \pm 0.001^{* *}$ & - \\
\hline \multirow[t]{3}{*}{$\alpha$} & Coast & $-0.089 \pm 0.044^{*}$ & $-0.089 \pm 0.044^{*}$ & - & $-0.099 \pm 0.044^{*}$ & $-0.11 \pm 0.04^{*}$ & - \\
\hline & No. of parameters & 13 & 12 & 11 & 10 & 10 & 7 \\
\hline & $\Delta \mathrm{AIC}$ & -43.20 & -42.92 & -40.75 & -33.10 & -29.88 & -17.14 \\
\hline
\end{tabular}




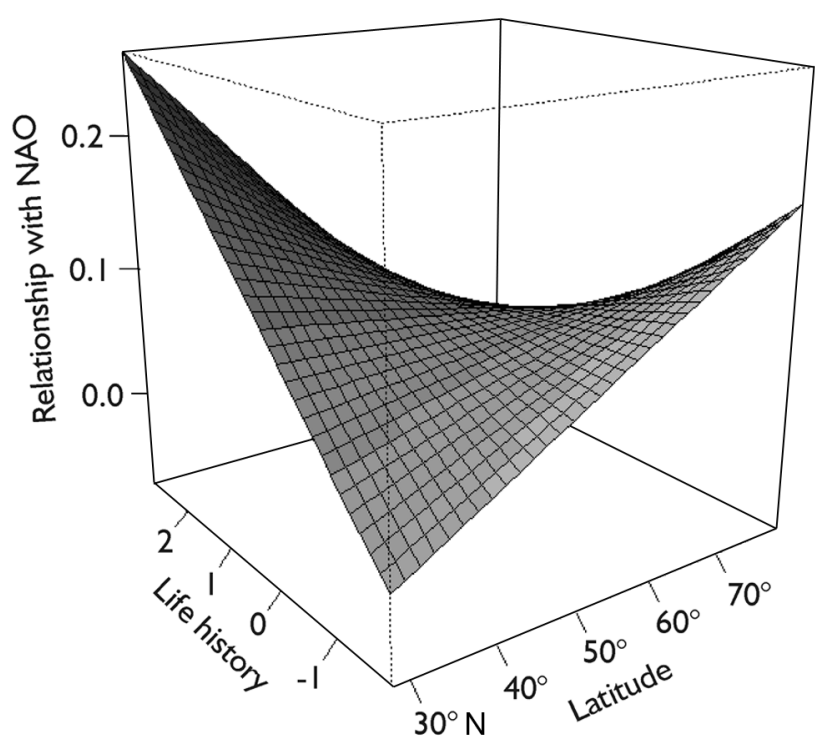

Fig. 2. Relationship between population growth rate and the North Atlantic Oscillation (NAO) across 378 North Atlantic seabird populations is affected by life history and latitude. Overall, the relationship with the NAO increases with faster life histories (Table 3), this pattern becoming weaker and even reversing towards the north. (The climatic covariate, $\mathrm{NAO}$, is lagged by each species' age at maturity. Life history is represented as a species' 'demographic speediness', i.e. high values indicate comparatively large clutches and low ages at maturity.)

Overall, the time lag with the most explanatory power was age at maturity (AIC increased by $>25$ units when omitting these effects; Table 3). The second most important time lag was $1 \mathrm{yr}(\Delta \mathrm{AIC}=13)$. Omitting the unlagged effects still deteriorated the model by almost 10 AIC units.

The only random factor retained in models of relationship with the NAO was the population. The variation at the species or higher taxon level was negligible $(\mathrm{SD}<0.005$; residual $=0.176)$.

There was no evidence of phylogenetic inertia in relationship with the NAO (all $\mathrm{r}_{\text {phylo }}^{2}<0.16, \mathrm{p}>0.2$ ). Climatic responsiveness showed considerable phylogenetic inertia at Time Lags $0\left(\mathrm{r}_{\text {phylo }}^{2}=0.35, \mathrm{p}=0.021\right)$ and $1\left(\mathrm{r}_{\text {phylo }}^{2}=0.30, \mathrm{p}=0.031\right)$, but not so at the time lag equalling age at maturity $\left(\mathrm{r}_{\text {phylo }}^{2}=0.14, \mathrm{p}=0.17\right)$.

\section{DISCUSSION}

\section{Relative importance of climatic effects on recruitment and adult survival}

The population dynamics in 378 populations of 29 different species of North Atlantic seabirds are shown to be clearly affected by climate, as measured by the NAO index. The most important time lag at which climate effects operated, was not a constant lag, but one that varied across species, viz. the one that corresponded to each individual species' age at maturity. In the sample considered, ages at maturity varied between 2 and 9 yr.

A time lag in population dynamics equalling age at maturity is caused by the recruitment of new breeders to the adult population. Finding that the effect of climate is most pronounced at this time lag, therefore, means that offspring production is the fitness component in North Atlantic seabirds that responds most to climatic variability. The findings thus have a direct bearing on what has been termed 'tap/tub hypothesis' (Sæther et al. 2004), i.e. the question whether population dynamics are mainly affected through offspring production and recruitment ('tap' hypothesis) or through adult survival ('tub' hypothesis). As the underlying processes are not mutually exclusive, however, one might better speak of 'tap' and 'tub' effects than of competing hypotheses. Our results show that both effects are relevant in seabirds; however, the 'tap' effect is more pronounced.

The latter finding is in accordance with the expectation that adult survival in seabirds should exhibit low temporal variability. In long-lived species such as seabirds, adult survival is the life-history parameter of greatest importance for population growth rate, i.e. the trait with the greatest elasticity (Gadgil \& Bossert 1970, Lebreton \& Clobert 1991, Wooller et al. 1992). At the same time, natural selection canalises the most elastic life-history traits, so that a negative correlation between elasticity and temporal variance is expected and found (Pfister 1998, Sæther \& Bakke 2000, Wisdom et al. 2000, Jonsson \& Ebenman 2001, Gaillard \& Yoccoz 2003). Empirical data from seabirds corroborate that adult survival has high elasticity and low temporal variability (Jenouvrier et al. 2005b, Stahl \& Oli 2006). It seems rather intuitive that a low temporal variability translates into a low climatic responsiveness of the trait in question.

The latter conclusion does not follow with necessity, however: the high elasticity of adult survival might also lead to the opposite expectation, viz. that even a relatively small response of adult survival to climatic variation may have a greater effect on long-term population growth than a comparatively much greater response in reproduction would have (cf. Eq. 1). After all, population viability is affected more by changes in the environ- 
ment that increase the temporal variance in demographic traits with high elasticity than in traits with low elasticity (Lande 1993, Sæther \& Bakke 2000). If, for instance, the climatic variability during the past decades exceeded the levels that a species has been adapted to (in either variance or mean), one might observe maladaptive responses even in highly elastic parameters. Several recent studies have documented effects of climate on seabird survival in the North Atlantic (Grosbois \& Thompson 2005, Harris et al. 2005, Sandvik et al. 2005, Frederiksen et al. 2008, Lavers et al. 2008). The current study, too, demonstrates that a nontrivial fraction of the climatic impacts on population dynamics is due to adult survival (Table 3). It might be feared that these effects are evidence of maladaptive responses to atypical conditions. However, the present study clearly shows that, at least when averaged across seabird species, population dynamics have so far been more strongly affected by climate through offspring production than through adult survival.

Several factors make it difficult to obtain reliable estimates of the magnitude of environmental effects on population dynamics that are exerted through recruitment. The most important among these factors are the prolonged recruitment period in long-lived species and the variance and uncertainty of age at maturity. Because immature birds are not counted as part of the breeding population, they are 'invisible' to population models during the 2 to $9 \mathrm{yr}$ (or more) prior to the birds' recruitment. The environmental influences (climatic and otherwise) that accumulate during this period and lead to pre-breeding mortality or emigration may be expected to erase or swamp the effect that climate has had on any given cohort during breeding. Furthermore, the birds of a given cohort do not all recruit in the same year. Finally, birds may return to their breeding colony several years before they in fact start to breed (Sandvik et al. 2008b). Most studies making up the raw data of our sample ( $\mathrm{n}=$ $378)$ used actual breeding pairs $(\mathrm{n}=258)$ or nests occupied ( $\mathrm{n}=71$ ) as their counting unit, however, minimising this error source. In any case, all the factors mentioned render our estimates conservative; in other words, our estimate is, if anything, an underestimate of the climatic impact on population dynamics via recruitment.

Similar to the response of adult survival, the response of offspring production to climate may itself be lagged because the effect is mediated through the food chain. Across species, however there was no evidence of the lag being longer than age at maturity (Table 1).

\section{Relationship with the NAO}

We examined whether the interspecific variation in climatic responses could be explained using the life history or feeding ecology of the species, or the geography of the populations. The relationship with the NAO lagged by age at maturity exhibited a striking difference between species with comparatively fast and slow life histories (i.e. large vs. 1-egg clutches, and low vs. high age at maturity; for discussions of the slow-fast life history continuum see Sæther \& Bakke 2000, Bennett \& Owens 2002). Among 'fast' species, the relationship with the NAO decreased with increasing latitude (Fig. 2). This result corroborates earlier findings from the analysis of breeding success (Sandvik et al. 2008a) and shows that the patterns found for breeding success retain their relevance for population dynamics throughout the entire pre-recruitment period. The findings are further strengthened by the fact that only 17 populations entered into both analyses (corresponding to $52 \%$ of the time series used in the earlier study and merely $4 \%$ of the current study). However, the current study extends the earlier results by showing that the decrease of the NAO relationship with latitude is restricted to species with fast life histories (Fig. 2, Table 3). While species with slow life histories (clutches of 1) respond much less to climate, 'fast' species exhibit positive relationships with the NAO at southern latitudes and negative relationships at northern latitudes. A possible explanation for this pattern is that recruitment is more variable in species with large clutches, being a consequence of the fact that the lowest possible recruitment is the same (viz., 0 ) irrespective of clutch size, while the maximum possible recruitment will increase with clutch size. Climatic effects on fecundity will thus result in larger impacts on population dynamics if clutch sizes are large. That the effect actually changes its sign is, in turn, most likely due to the different oceanographic 'meaning' of the NAO at different latitudes (Wang et al. 2004, Sandvik et al. 2008a).

The relationship between population growth rate and climate differed among populations on the American and European coasts of the North Atlantic. This could be due to differences in the marine environment and the meteorological 'meaning' of the NAO on the 2 coasts, i.e. due to different relationships between regional and local climate (cf. Hurrell et al. 2003). 
Owing to hugely differing sample sizes $\left(\mathrm{n}_{\mathrm{Am}}=21, \mathrm{n}_{\text {Eur }}\right.$ = 357) and the fact that the American data only came from terns and pelicans, the difference may also be an artefact, e.g. because these taxa have lower average annual adult survival rates $(0.825 \pm 0.025)$ than other seabird groups $(0.879 \pm 0.010$; based on the species sampled for the present paper). Interestingly, the signs of the effect are not the same at the 3 time lags considered: the relationship between the unlagged winter NAO and the population growth rate is more positive in Europe than in America. However, the relationship is more positive in America than in Europe for longer time lags. This indicates that, on average, a NAO condition that exerts a negative effect on adult survival, has a positive effect on reproduction in the following breeding season, and vice versa.

\section{Climatic responsiveness}

In analysing climatic effects on population dynamics, we distinguished between the relationship with the NAO and climatic responsiveness (see 'Methods' for definitions). The latter variable ignores the sign of the climatic effects while retaining its magnitude. Previous studies have shown that large climatic effects of different signs can cancel each other out in analyses where effects are averaged across multiple populations of the same species (Sandvik \& Erikstad 2008, Sandvik et al. 2008a), so that climatic responsiveness might be interpreted as a propensity or potential of a species rather than a fixed attribute. The actually realised magnitude and even sign of the climatic response may vary on comparatively small geographical scales due to local oceanographic, trophic, or other conditions (Sæther et al. 2003, 2004, Harris et al. 2005, Irons et al. 2008). This explanation is compatible with our findings: the present study has documented different average signs of relationship with the NAO at different latitudes; there was considerable phylogenetic inertia in climatic responsiveness, but not in relationship with the $\mathrm{NAO}$; and species and higher taxon were rejected as random effects in models of relationship with the NAO, but could not be omitted in models of climatic responsiveness.

Climatic responsiveness lagged by age at maturity showed a marginal trend to decrease with the population's latitude. According to the model that obtained the lowest AIC value (Table 2), there was also a very weak positive effect of body mass on climatic responsiveness; however, none of these models outperformed the more parsimonious model without covariates (Table 1).
It has been suggested that foraging range or diving depth can predict the responsiveness of seabirds to environmental variation (Furness \& Ainley 1984, Furness \& Barrett 1991, Furness \& Tasker 2000). In our dataset, however, apart from some weakly supported tendencies (cf. Table 2), feeding ecology did not explain any across-species variance in climatic responses.

\section{Methodological considerations}

The use of a high number of time lags and the estimation of a nuisance parameter $\mathrm{\kappa}$ turned out to be an effective way of providing unbiased estimates of the time lag and magnitude of demographic responses to climatic variability (cf. Fig. 1 and Eq. 4). The estimates were, therefore, not affected by the length of the time series or the quality of the data. The analysis did not correct for the presence of observation error in population counts, e.g. due to intermittent breeding or methodological limitations. Likewise, the relationships with the NAO-being estimates from population models and not measurements - were treated as point estimates in subsequent analyses, which amounts to an additional simplifying assumption. However, the fact that data quality did not affect the estimates, gives some indication that the results are robust, at least against a certain level of observation error. This would have to be verified using methods that are able to quantify observation error and to take error propagation into account, however.

A number of other factors remains uncorrected for, such as non-linear responses to climate or different strengths and forms of density regulation in different species (Sæther \& Engen 2010a). While providing topics for further detailed study of single species, it may be premature to address these issues at the cross-specific level. In the analyses presented here, these factors most likely take the form of noise rather than systematic errors.

In age-structured populations, apparent environmental effects that are lagged by the age at maturity may occur purely because of autocorrelations in the population time series (Lande et al. 2002, 2003). This potential artefact cannot account for the findings reported here, because, in this case, the same environmental covariates would also show an unlagged effect of the same sign and an even greater magnitude. To the contrary, the climatic effect lagged by age at maturity was actually stronger than the unlagged one and had the opposite sign. 


\section{Conclusions and outlook}

To summarise, we found evidence in an interspecific dataset that the population dynamics of North Atlantic seabirds are affected by climate, both through an effect on offspring production and on adult survival. Although the climatic signal of offspring production on population dynamics is weakened by conditions experienced by immature birds during the years prior to recruitment, this effect had nevertheless the greatest magnitude.

The current warming of global climate, which is predicted to continue and accelerate during the next century at least (IPCC 2007), will doubtlessly affect seabirds, too. Given that the patterns documented in the present study using data from the past century (1920 to 2005) hold true for the next century, too, our findings allow some predictions about seabird population responses to climatic change.

First, the signs of the climate effects differed for different time lags: climate conditions that affect population growth rate negatively by unlagged effects on adult survival tend to have positive effects on population growth rate by lagged effects via offspring recruitment, and vice versa. This finding, which has also been reported from the Southern Hemisphere (Croxall et al. 2002, Jenouvrier et al. 2005a), may entail a certain amount of buffering of population dynamics against climatic variability.

On the other hand, if positive-phase NAO conditions become more frequent in the future, as has been predicted based on coupled general circulation models (Monahan et al. 2000), the following responses of seabird population may be predicted: species of Atlantic seabirds with small clutches and high annual adult survival rates will tend to exhibit lower population growth rates (or more decreasing long-term trends) than species with the opposite life-history strategy. This difference will be most pronounced for populations breeding at lower latitudes.

Acknowledgements. We thank all the researchers who have collected and published time series on seabird population sizes. Special thanks are due to the British and Norwegian seabird monitoring programs for permission to use their data (Mavor et al. 2002, Lorentsen 2006). Elizabeth A. Schreiber has kindly made her database on seabird life history available to us (Schreiber \& Burger 2002). We are grateful to Vidar Grøtan for providing and adjusting the script used for modelling population dynamics. The study was carried out with financial support from the Norwegian Research Council (NORKLIMA) and NTNU (core funding to the CCB). The manuscript was substantially improved by the comments of 3 anonymous reviewers.

\section{LITERATURE CITED}

Barnston AG, Livezey RE (1987) Classification, seasonality and persistence of low-frequency atmospheric circulation patterns. Mon Weather Rev 115:1083-1126

Bennett PM, Owens IPF (2002) Evolutionary ecology of birds: life histories, mating systems, and extinction. In: Harvey $\mathrm{PH}$, May RM (eds) Oxford series in ecology and evolution, Book 24. Oxford University Press, Oxford

Caswell H (2001) Matrix population models: construction, analysis, and interpretation, 2nd edn. Sinauer, Sunderland

- Croxall JP, Trathan PN, Murphy EJ (2002) Environmental change and Antarctic seabird populations. Science 297:1510-1514

> Durant JM, Anker-Nilssen T, Hjermann DØ, Stenseth NC (2004a) Regime shifts in the breeding of an Atlantic puffin population. Ecol Lett 7:388-394

Durant JM, Stenseth NC, Anker-Nilssen T, Harris MP, Thompson PM, Wanless S (2004b) Marine birds and climate fluctuation in the North Atlantic. In: Stenseth NC, Ottersen G, Hurrell JW, Belgrano A (eds) Marine ecosystems and climate variation. Oxford University Press, Oxford, p 95-105

Engen S, Lande R, Sæther BE, Dobson S (2009) Reproductive value and the stochastic demography of age-structured populations. Am Nat 174:795-804

Frederiksen M, Daunt F, Harris MP, Wanless S (2008) The demographic impact of extreme events: stochastic weather drives survival and population dynamics in a long-lived seabird. J Anim Ecol 77:1020-1029

Furness RW, Ainley DG (1984) Threats to seabird populations presented by commercial fisheries. In: Croxall JP, Evans PGH, Schreiber RW (eds) Status and conservation of the world's seabirds. International Council for Bird Preservation, Cambridge, p 701-708

Furness RW, Barrett RT (1991) Ecological responses of seabirds to reductions in fish stocks in North Norway and Shetland. In: Bell BD (ed) Acta XX Congressus Internationalis Ornithologici. New Zealand Ornithological Congress Trust Board, Wellington, p 2241-2245

> Furness RW, Tasker ML (2000) Seabird-fishery interactions: quantifying the sensitivity of seabirds to reductions in sandeel abundance, and identification of key areas for sensitive seabirds in the North Sea. Mar Ecol Prog Ser 202:253-264

Gadgil M, Bossert WH (1970) Life historical consequences of natural selection. Am Nat 104:1-24

Gaillard JM, Yoccoz NG (2003) Temporal variation in survival of mammals: a case of environmental canalization? Ecology 84:3294-3306

> Gaston AJ, Gilchrist HG, Mallory ML, Smith PA (2009) Changes in seasonal events, peak food availability, and consequent breeding adjustment in a marine bird: a case of progressive mismatching. Condor 111:111-119

Gilpin ME, Ayala FJ (1973) Global models of growth and competition. Proc Natl Acad Sci USA 70:3590-3593

Grosbois V, Thompson PM (2005) North Atlantic climate variation influences survival in adult fulmars. Oikos 109:273-290

Grøtan V, Sæther BE, Lillegård M, Solberg EJ, Engen S (2009) Geographical variation in the influence of density dependence and climate on the recruitment of Norwegian moose. Oecologia 161:685-695 
Harris MP, Anker-Nilssen T, McCleery RH, Erikstad KE, Shaw DN, Grosbois V (2005) Effect of wintering area and climate on the survival of adult Atlantic puffins Fratercula arctica in the eastern Atlantic. Mar Ecol Prog Ser 297:283-296

Hurrell JW (2005) Climate indices. Available at: www. cgd.ucar.edu/cas/jhurrell/indices.html (accessed on 3 November 2005)

Hurrell JW, Kushnir Y, Ottersen G, Visbeck M (2003) An overview of the North Atlantic Oscillation. Geophys Monogr 134:1-35

IPCC (Intergovernmental Panel on Climate Change) (ed) (2007) Climate change 2007: the physical science basis. Contributions of Working Group I to the 4th assessment report of the Intergovernmental Panel on Climate Change. Cambridge University Press, Cambridge

Irons D, Anker-Nilssen T, Gaston AJ, Byrd GV and others (2008) Fluctuations in circumpolar seabird populations linked to climate oscillations. Glob Change Biol 14: 1455-1463

Jenouvrier S, Barbraud C, Weimerskirch H (2005a) Longterm contrasted responses to climate of two Antarctic seabird species. Ecology 86:2889-2903

> Jenouvrier S, Barbraud C, Cazelles B, Weimerskirch H (2005b) Modelling population dynamics of seabirds: importance of the effects of climate fluctuations on breeding proportions. Oikos 108:511-522

> Jenouvrier S, Thibault JC, Viallefont A, Vidal P and others (2009) Global climate patterns explain range-wide synchronicity in survival of a migratory seabird. Glob Change Biol 15:268-279

> Jonsson A, Ebenman B (2001) Are certain life histories particularly prone to local extinction? J Theor Biol 209: 455-463

Kitaysky AS, Golubova EG (2000) Climate change causes contrasting trends in reproductive performance of planktivorous and piscivorous alcids. J Anim Ecol 69:248-262

Lande R (1993) Risks of population extinction from demographic and environmental stochasticity and random catastrophes. Am Nat 142:911-927

- Lande R, Engen S, Sæther BE (2002) Estimating density dependence in time-series of age-structured populations. Philos Trans R Soc Lond B Biol Sci 357:1179-1184

Lande R, Sæther BE, Engen S (2003) Stochastic population dynamics in ecology and conservation. Oxford University Press, Oxford

- Lavers JL, Jones IL, Diamond AW, Robertson GJ (2008) Annual survival of North American razorbills (Alca torda) varies with ocean climate indices. Can J Zool 86:51-61

Lebreton JD, Clobert J (1991) Bird population dynamics, management, and conservation: the role of mathematical modelling. In: Perrins CM, Lebreton JD, Hirons GJM (eds) Bird population studies. Oxford University Press, Oxford, p 105-125

> Lee DE, Nur N, Sydeman WJ (2007) Climate and demography of the planktivorous Cassin's auklet Ptychoramphus aleuticus off northern California: implications for population change. J Anim Ecol 76:337-347

Lorentsen S-H (2006) Det nasjonale overvåkingsprogrammet for sjøfugl. Resultater til og med hekkesesongen 2006. Nor Inst Naturforsk Rapp 203:1-53

Mavor RA, Pickerell G, Heubeck M, Mitchell PI (2002) Seabird numbers and breeding success in Britain and Ireland, 2001. Joint Nature Conservation Committee, Peterborough
Monahan AH, Fyfe JC, Flato GM (2000) A regime view of northern hemisphere atmospheric variability and change under global warming. Geophys Res Lett 27:1139-1142

Monticelli D, Ramos JA, Quartly GD (2007) Effects of annual changes in primary productivity and ocean indices on breeding performance of tropical roseate terns in the western Indian Ocean. Mar Ecol Prog Ser 351:273-286

> Mysterud A, Yoccoz NG, Stenseth NC, Langvatn R (2000) Relationships between sex ratio, climate and density in red deer: the importance of spatial scale. J Anim Ecol 69:959-974

Ottersen G, Planque B, Belgrano A, Post E, Reid PC, Stenseth H (2001) Ecological effects of the North Atlantic Oscillation. Oecologia 128:1-14

> Pfister CA (1998) Patterns of variance in stage-structured populations: evolutionary predictions and ecological implications. Proc Natl Acad Sci USA 95:213-218

Pinheiro J, Bates D, DebRoy S, Sarkar D (2006) nlme: linear and nonlinear mixed effects models, Version 3.1-78. R Foundation for Statistical Computing, Wien

Poole A, Gill F (eds) (1992-2003) The birds of North America: life histories for the 21st century. Academy of Natural Sciences, Philadelphia, PA, and American Ornithologists' Union, Washington, DC

Post E (2004) Time lags in terrestrial and marine environments. In: Stenseth NC, Ottersen G, Hurrell JW, Belgrano A (eds) Marine ecosystems and climate variation. Oxford University Press, Oxford, p 165-167

R Development Core Team (2006) R: a language and environment for statistical computing, Version 2.4.1. R Foundation for Statistical Computing, Wien

Reid JB, Becker PH, Furness RW (1999) Evidence for decadal scale variations in seabird population ecology and links with the North Atlantic Oscillation. ICES Coop Res Rep 232:47-50

Sæther BE, Bakke $\varnothing$ (2000) Avian life history variation and contribution of demographic traits to the population growth rate. Ecology 81:642-653

Sæther BE, Engen S (2002) Pattern of variation in avian population growth rates. Philos Trans R Soc B Biol Sci 357 : 1185-1195

Sæther BE, Engen S (2010a) Population analyses. In: Møller AP, Fiedler W, Berthold P (eds) Effects of climate change on birds. Oxford University Press, Oxford, p 67-75

Sæther BE, Engen S (2010b) Population consequences of climate change. In: Møller AP, Fiedler W, Berthold P (eds) Effects of climate change on birds. Oxford University Press, Oxford, p 191-211

Sæther BE, Engen S, Møller AP, Matthysen E and others (2003) Climate variation and regional gradients in population dynamics of two hole-nesting passerines. Proc R Soc Lond B Biol Sci 270:2397-2404

Sæther BE, Sutherland WJ, Engen S (2004) Climate influences on avian population dynamics. Adv Ecol Res 35:185-209

Sæther BE, Grøtan V, Engen S, Noble DG, Freckleton RP (2009) Critical parameters for predicting population fluctuations of some British passerines. J Anim Ecol 78: 1063-1075

Sandvik H, Erikstad KE (2008) Seabird life histories and climatic fluctuations: a phylogenetic-comparative time series analysis of North Atlantic seabirds. Ecography 31: 73-83

Sandvik H, Erikstad KE, Barrett RT, Yoccoz NG (2005) The effect of climate on adult survival in five species of North Atlantic seabirds. J Anim Ecol 74:817-831 
Sandvik H, Coulson T, Sæther BE (2008a) A latitudinal gradient in climate effects on seabird demography: results from interspecific analyses. Glob Change Biol 14:703-713

Sandvik H, Erikstad KE, Fauchald P, Tveraa T (2008b) High survival of immatures in a long-lived seabird: insights from a long-term study of the Atlantic puffin (Fratercula arctica). Auk 125:723-730

Schreiber EA, Burger J (2002) Data on life-history characteristics, breeding range, size and survival for seabird species. In: Schreiber EA, Burger J (eds) Biology of marine birds. CRC, Boca Raton, FL, p 665-685

Stahl JT, Oli MK (2006) Relative importance of avian lifehistory variables to population growth rate. Ecol Modell 198:23-39

Stearns SC (1992) The evolution of life histories. Oxford University Press, Oxford

Sydeman WJ (ed) (2009) Marine ecosystems, climate and phenology: impacts on top predators. Mar Ecol Prog Ser 393:185-188

> Thompson PM, Ollason JC (2001) Lagged effects of ocean

Submitted: April 11, 2011; Accepted: December 11, 2011 climate change on fulmar population dynamics. Nature 413:417-420

Tuljapurkar S, Gaillard JM, Coulson T (2009) From stochastic environments to life histories and back. Philos Trans R Soc B Biol Sci 364:1499-1509

Wang W, Anderson BT, Kaufmann RK, Myneni RB (2004) The relation between the North Atlantic Oscillation and SSTs in the North Atlantic Basin. J Clim 17:4752-4759

Weimerskirch H, Inchausti P, Guinet C, Barbraud C (2003) Trends in bird and seal populations as indicators of a system shift in the Southern Ocean. Antarct Sci 15:249-256

Wisdom MJ, Mills LS, Doak DF (2000) Life stage simulation analysis: estimating vital-rate effects on population growth for conservation. Ecology 81:628-641

Wolf SG, Sydeman WJ, Hipfner JM, Abraham CL, Tershy BR, Croll DA (2009) Range-wide reproductive consequences of ocean climate variability for the seabird Cassin's auklet. Ecology 90:742-753

Wooller RD, Bradley JS, Croxall JP (1992) Long-term population studies of seabirds. Trends Ecol Evol 7:111-114

Proofs received from author(s): March 23, 2012 